\title{
Learning in infant rats: Escape from cold
}

\author{
CHARLES F. HINDERLITER \\ Furman University, Greenville, South Carolina 29613
}

and

\author{
JAMES R. MISANIN, DONALD F. BAKER, and FREDRICK M. TOPPER \\ Susquehanna University, Selinsgrove, Pennsylvania 17870
}

\begin{abstract}
The results of a number of studies indicate that rats and mice as young as 7 days of age are capable of learning an escape task. Because in all of these studies footshock was used as the negative reinforcer, it was considered necessary to determine if other negative reinforcers could support learning in infant rodents. Accordingly, 7- and 9-day-old rats were given escape training in a straight alley, during which removal from a cold grid-like floor served as reinforcement. In comparison with yoked controls, trained subjects showed little evidence of learning. Twenty-four hours later, these same animals and naive control animals were given retraining and training sessions, respectively. While there was little evidence of a residual effect of the initial training or yoked control experience, all 10-day-old age groups showed an intrasession increase in speed and an intrasession decrease in competing responses. It was concluded, therefore, that a cold-inducing stimulus can also serve as an effective reinforcer in the escape training of infant rats.
\end{abstract}

When exposed to aversive stimulation, perinatal rats and mice typically show a pivoting or turning reaction. The types of situations examined include falling from the nest (Bolles \& Woods, 1964), suspension over cold water or ammonia (Gard, Hard, Larsson, \& Peterson, 1967), and contact with grid shock (Misanin, Haigh, Hinderliter, \& Nagy, 1973). In a number of studies on escape behavior in infant rodents, it has been shown that a decrease in turning responses can be indicative of learning (Misanin et al., 1973; Nagy, Burley, \& Kikstadt, 1977; Nagy, Misanin, \& Newman, 1970). While all of these studies employed footshock as the negative reinforcer, one might predict that other types of aversive stimulation that elicit turning might also serve as effective reinforcers in the escape situation. To test this prediction and, hence, to gain information on the general effectiveness of negative reinforcers in the training of infant rodents, the present study examined the escape-from-cold behavior of 7- to 10-day-old rats.

\section{METHOD}

\section{Subjects}

Wistar rats born in the Susquehanna University animal colony served as subjects. Three males and three females from each of six litters were used. Three same-sex rats from each litter were assigned to each of two age groups.

This research was supported in part by a Faculty Summer Research Grant from Susquehanna University to James R. Misanin. Requests for reprints should be sent to Charles F. Hinderliter, Furman University, Greenville, South Carolina 29613.

\section{Apparatus}

A $25.5 \times 6.8 \times 9.7 \mathrm{~cm}$ acrylic runway was used for escape training. The runway was placed atop a $30.5 \times 13.7 \times 5.5 \mathrm{~cm}$ watertight acrylic box through which $2^{\circ} \mathrm{C}-3^{\circ} \mathrm{C}$ water was continuously pumped from a Forma Temp. Jr. (Model 2095) bath and circulator. The top of this acrylic box was grooved (4 $\mathrm{mm}$ deep) at 2-mm intervals to give it a grid-like appearance and texture. The temperature of this grooved top was continuously monitored with a Yellow Springs Tele-Thermometer (Model 43TD) and maintained at $10^{\circ} \mathrm{C}-14^{\circ} \mathrm{C}$. Thus, the grooved acrylic top served as the cold, dry, grid-like floor of the runway.

\section{Procedure}

Six 7-day-old and six 9-day-old rats were each given 25 escape training trials on Day 1. A trial began when a rat was placed in the start section of the runway facing the goal end. A trial ended when the subject touched the goal-end wall opposite the start section or after $120 \mathrm{sec}$. If the rat failed to reach the goal end in $120 \mathrm{sec}$, it was gently pushed to the end (forced trial). Immediately upon reaching the goal end, each rat was removed and enclosed in the experimenter's hand for a 45-sec intertrial interval (ITI).

On each trial, the time it took the animal to reach the goal (escape latency) was recorded to the nearest $.1 \mathrm{sec}$. For a forced trial, a latency of $120 \mathrm{sec}$ was recorded. Also recorded was the number of 180-deg turns away from the goal (competing response). Thus, after a 180-deg turn away from the goal, a return to the start position (i.e., facing the goal) was necessary before another such competing response could be made.

Also on Day 1, a subgroup of six rats from each age group was treated as a yoked control group. This treatment involved placing the animal on the cold grid-like floor of the runway for the same length of time that its trained littermate spent in the runway on each trial. Thus, for the yoked subjects, removal from the runway was determined not by their performance but on the basis of the time taken by trained littermates to perform the escape response. Yoked animals were also enclosed in the experimenter's hand during the 45-sec ITI. On each yoked subject's trial, the number of 180 -deg turns was recorded. Also 
noted were the trials on which the animal remained in the start section and those on which the animal reached the goal end of the runway.

The remaining six animals in each age group were not trained on Day 1 and served as naive controls. Their performance on the next day served as a means of assessing the relative contribution of maturation in the escape performance of the trained and yoked subjects on Day 2.

On Day 2, the three subgroups at each age level were given 25 escape training trials. These trials were identical to those given to the trained subjects on Day 1. Response measures obtained on each of these trials were number of competing responses and escape latency. Records of each subject's forced trials and trials without competing responses were also kept.

\section{RESULTS}

\section{Day 1}

All response measures were averaged over five-trial blocks. The mean numbers of competing responses per five-trial block as a function of age and treatment (trained vs. yoked) are shown in Figure 1. A 2 (7 vs. 9 days) by 2 (trained vs. yoked) by 5 (Trial Blocks 1-5) split-plot factorial analysis (SPF-22.5) of variance (Kirk, 1968) was performed on the competing-response data. Only a significant main effect of trial block was obtained $[F(4,80)=38.9, p<.001]$. Newman-Keuls comparisons between first and last trial blocks revealed that all groups significantly decreased competing responses over trial blocks $(p<.05)$.

Speed (reciprocal latency) on each of the trial blocks was, for the 7-day-olds, .010, .009, .008, .008, and .009 . For the 9-day-olds, the mean speed per trial block was $.009, .101, .019, .023$, and .009 for Trial Blocks 1-5, respectively. A split-plot factorial analysis of variance (SPF-2.5) of the speed data failed to reveal any significant main or interaction effects. Similarly, a SPF-2.5 analysis of variance of the forced-trial data yielded no significant age, trial block, or interaction effects. The mean numbers of forced trials as a function of trial block for the 7-day-olds were 4.2, 4.3, 4.8, 5.0, and 4.5; for the 9-day-olds, they were 4.3, 4.7, 3.7, 3.7, and 3.8.

The speed and forced-trial data indicate that the decrease in competing responses observed in the trained subjects is not indicative of learning the escape response (Misanin et al., 1973) and, hence, escape from cold is not an effective reinforcer for 7- and 9-day-old rats. The speed and forced-trial data suggest that the decrease in competing responses may be, simply, the results of inactivity produced by cold. Not only were the trained subjects inactive, but the yoked subjects also decreased activity over training. This was indicated by the finding that not only did they decrease their 180-deg turns, but they showed an intrasession increase in the number of trials in which they remained in the start section $[F(4,40)=4.06, p<.009]$ and a significant decrease in the number of trials on which they reached the goal end of the runway $[F(4,40)=3.29, \mathrm{p}<.02]$.
Day 2

Each of the four response measures (competing responses, reciprocal escape latency, forced trials, and trials without competing responses) was subjected to a SPF-23.5 analysis of variance in which age (animals were now 8 and 10 days old), treatment (previously trained, yoked, or not trained), and trial block (Blocks 1-5) were the factors under consideration. Newman-Keuls tests, at the .05 level of significance, were used in making a posteriori comparisons.

An analysis of the competing response data (Figure 2) revealed a significant main effect of trial block $[F(4,120)=97.9, \mathrm{p}<.001]$ and a nonadditive Age by Trial Block interaction $[\mathrm{F}(4,120)=2.38, \mathrm{p}<.055]$. The 10-day-old rats made significantly fewer competing responses than the 8-day-olds in the middle of the training session.

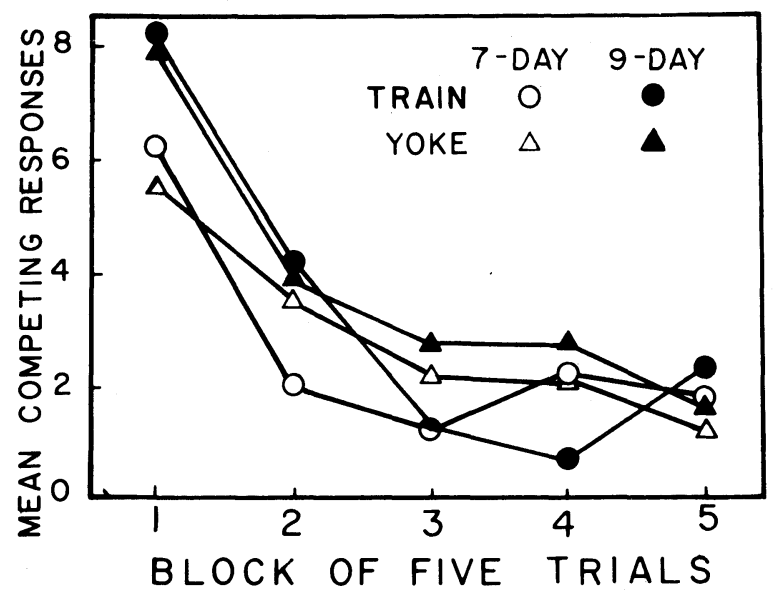

Figure 1. Mean competing responses per five-trial block of the trained and yoked animals on Day 1 as a function of age.

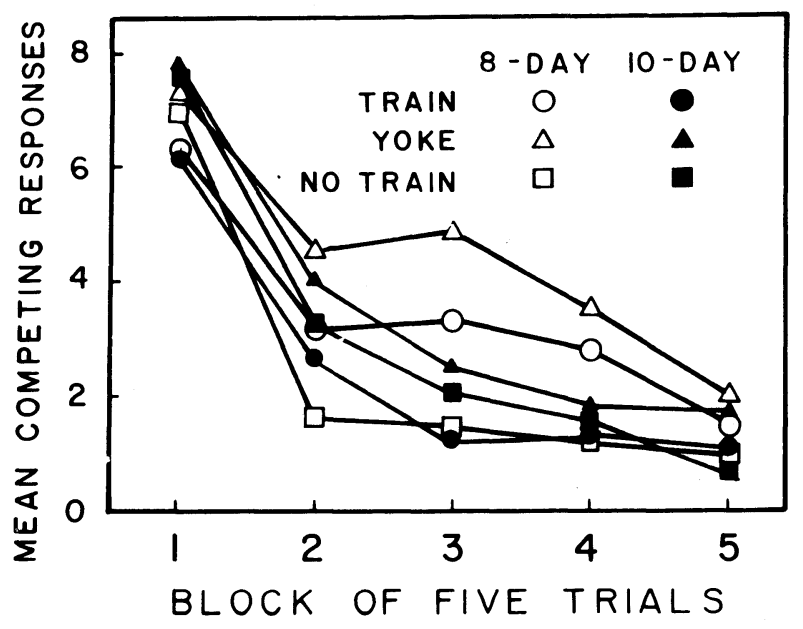

Figure 2. Mean competing responses per five-trial block on Day 2 as a function of age and the treatment administered on Day 1. 
The analysis of trials without competing responses also yielded a significant main effect of trial block $[F(4,120)=55.8, p<.001]$ and a significant Age by Trial Block interaction $[\mathrm{F}(4,120)=2.55, \mathrm{p}<.042]$. Again, the performance of the 10-day-olds was significantly superior to that of the 8-day-olds in midsession. The mean numbers of trials without competing responses over Trial Blocks 1-5 were, for the 8- and 10day-olds, respectively, .6, 2.1, 2.3, 2.6, 3.6, and .4, 2.4, 3.2, 3.6, 3.8.

The analysis of the speed (reciprocal latency) data indicated significant main effects of age $[\mathrm{F}(1,30)=$ $16.44, p<.001]$ and trial block $[F(4,120)=13.25$, $\mathrm{p}<.001]$, and a significant interaction of these factors $[F(4,120)=14.09, p<.001]$. The nature of this interaction is evident in Figure 3. Younger rats failed to increase speed of escape over training, whereas the older ones showed a significant intrasession increase in speed. It should be noted that even though there is a clear separation of trial block means of the trained 10-day-old subjects and those of their naive and yoked controls, this apparent difference is not statistically significant.

An analysis of the forced-trial data (Figure 4) yielded results very similar to those of the speed analysis. Again, the performance of the 10-day-olds significantly surpassed that of the 8-day-olds $[F(1,30)=18.33$, $\mathrm{p}<.001]$. And again, the apparent difference in the trial block means of the trained 10-day-olds and their naive controls was not statistically reliable.

\section{DISCUSSION}

While the Day 2 data show that there was no residual effect of either the training or yoked control treatment experienced on Day 1, they do indicate that escape from cold can support learning in 10-day-old rats. Not only did the competing responses and forced trials of the 10-day-olds decrease, but also trials without competing responses and speed increased. The Day 1 and Day 2 data on the 7-, 8-, and 9-day-olds, however, indicate that removal from the $10^{\circ} \mathrm{C}-14^{\circ} \mathrm{C}$ floor was ineffective as a reinforcer in the escape training of rats younger than 10 days of age. This ineffectiveness may have been the result of a combination of factors. Both locomotor ability (Altman \& Sudarshan, 1975; Bolles \& Woods, 1964) and escape efficiency (Misanin, Hardy, Goodyear, \& Nagy, 1974) are functions of age in the infant rat. Also, neonatal and infant rats are poikilothermic, with the rate of temperature drop decreasing linearly as age increases (Adolf, 1957). Thus, failure of escape from cold to support learning in the younger animals may have been due to either (1) an inability of the younger rats to learn the task fast enough to effectively reduce their exposure to cold and, hence, of fset any debilitating effects low body temperature may have on motor behavior and the neural process(es) involved in learning, or (2) the inability of the younger rats to move fast enough across the floor that there was a noticeable and reinforcing increment in temperature when they were removed from the apparatus.

On the other hand, it may be that a more effective coldinducing stimulus, perhaps cold air or cold water that lowers a floor to below $10^{\circ} \mathrm{C}-14^{\circ} \mathrm{C}$, will support learning in rats younger than 10 days of age.

In any event, the present study shows that a cold-inducing stimulus can serve as an effective reinforcer for rats as young as 10 days of age and, together with previous research (e.g.,

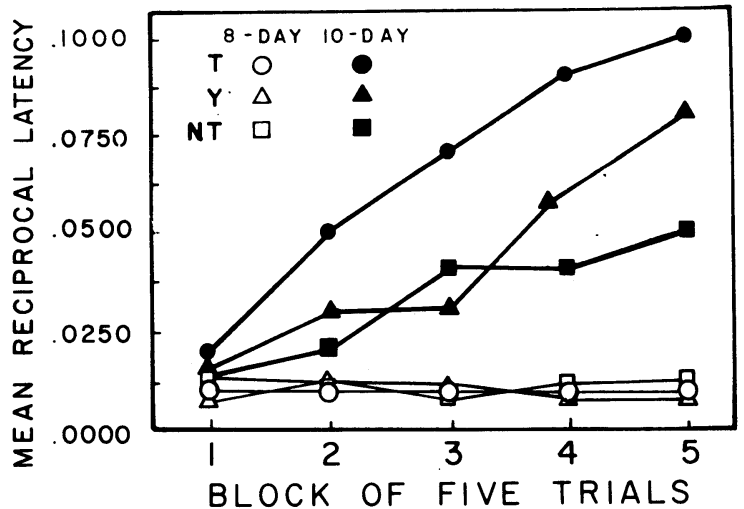

Figure 3. Mean speed (reciprocal latency) per five-trial block of the 8- and 10-day-old rats as a function of the treatment given on Day 1. T refers to training, $Y$ to yoked control, and NT to no training.

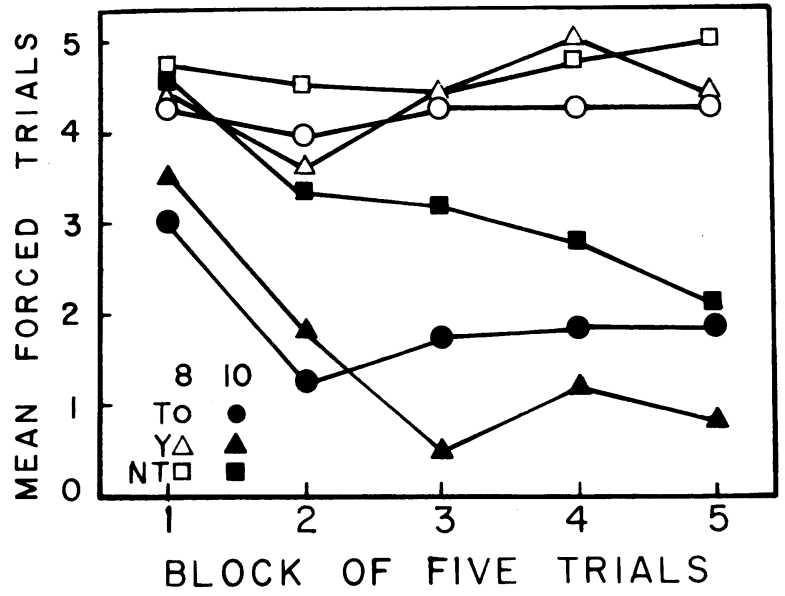

Figure 4. Mean number of forced trials per five-trial block of the trained (T), yoked (Y), and no-training (NT) 8- and 10-dayold rats.

Caldwell, Brand, \& Werboff, 1964; Caldwell \& Werboff, 1962; Gray, Yates, \& McNeal, 1967; Misanin, Chubb, Quinn, \& Schweikert, 1974; Misanin et al., 1973; Rudy \& Cheatle, 1977), indicates that negative reinforcers are, in general, effective in the conditioning and training of infant rats.

\section{REFERENCES}

Adolf, E. F. Ontogeny of physiological regulations in the rat. The Quarterly Review of Biology, 1957, 32, 89-137.

Altman, J., \& Sudarshan, K. Postnatal development of locomotion in the laboratory rat. Animal Behaviour, 1975, 23, 896-920.

Bolles, R. C., \& Woods, P. J. The ontogeny of behaviour in the albino rat. Animal Behaviour, 1964, 12, 427-441.

Caldwell, D. F., Brand, R., \& WerbofF, J. Effect of environmental temperature on conditioning in the new-born poikilothermic rat. Nature, 1962, 195, 1314-1315.

Caldwell, D. F., \& Werboff, J. Classical conditioning in newborn rats. Science, 1962, 136, 1118-1119.

Gard, C., Hard, E., Larsson, K., \& Peterson, V. The relationship between sensory stimulation and gross motor 
behaviour during postnatal development in the rat. Animal Behaviour, 1967, 15, 563-567.

Gray, P. H., Yates, A. E., \& McNeal, K. The ontogeny of classical conditioning in the neonatal rat with varied CS-UCS intervals. Psychonomic Science, 1967, 9, 587-588.

KIRK, R. E. Experimental design: Procedures for the behavioral sciences. Belmont, Calif: Brooks/Cole, 1968.

Misanin, J. R., Chubb, L. D., Quinn, S. A., \& Schweikert, G. E. An apparatus and procedure for effective instrumental training of neonatal and infant rats. Bulletin of the Psychonomic Society, 1974, 4, 171-173.

Misanin, J. R., Haigh, J. M., Hinderliter, C. F., \& Nagy, Z. M. Analysis of response competition in discriminated and nondiscriminated escape training of neonatal rats. Journal of Comparative and Physiological Psychology, 1973, 85, 570-580.
Misanin, J. R., Hardy, S., Goodyear, J., \& Nagy, Z. M. Effects of shock intensity on speed and response competition in the escape training of neonatal and infant rats. Bulletin of the Psychonomic Society, 1974, 2, 397-399.

Nagy, Z. M., Burley, J. W., \& Kikstadt, L. K. Competing response decrement as a measure of escape learning and memory in young mice: Effect of learned inhibition, maturation, or age-dependent shock sensitivity? Bulletin of the Psychonomic Society, 1977, 10, 21-24.

Nagy, Z. M., Misanin, J. R., \& Newman, J. The anatomy of escape behavior in neonatal mice. Journal of Comparative and Physiological Psychology, 1970, 72, 116-124.

Rudy, J. W., \& Cheatle, M. D. Odor-aversion learning in neonatal rats. Science, 1977, 198, 845-846.

(Received for publication August 28, 1978.) 